\title{
Pragma-dialectical analysis of rhetorical texts
}

\author{
The case of Barack Obama in Cairo
}

\author{
Dima Mohammed \& David Zarefsky
}

\section{The analytical problem}

Over the course of thirty years, Frans van Eemeren and his colleagues have articulated the pragma-dialectical perspective on argumentation (van Eemeren \& Grootendorst 2004). The most comprehensive extant theory of argumentation, pragma-dialectics accounts for situations in which people seek to resolve disagreements through reasoned discourse, beginning with commitments they share (Walton \& Krabbe 1995) and working toward a mutually satisfactory conclusion. It does so first by reconstructing ordinary-language statements into a dialectical structure that clarifies the relationships between standpoints an arguer defends and the challenges to those standpoints, as well as the relationship between an arguer's principal and supporting standpoints. Pragma-dialectics then evaluates the moves in the argumentative encounter by reference to the rules that should govern a critical discussion. A critical discussion is not an empirical case of argumentation but a normative ideal, although its norms are endorsed in large measure by actual arguers.

Pragma-dialectics examines interactive arguments, those in which (usually) two arguers advance, defend, and challenge standpoints in a sequential fashion, through which their moves can be identified and scrutinized. And the analysis assumes that the arguers' goal is to resolve disagreements in a reasoned manner. Neither of these assumptions, of course, is a universal characteristic of argumentation. Some arguments have persuasion of another arguer as the principal goal, whereas others seek to test hypotheses, to discover one's own beliefs, to advance or to undermine a personal relationship, to impress another person with one's own reasoning ability, or even to argue for arguing's own sake. Likewise, many arguments are not sequential in nature. They may be embodied in a written text, public speech, or visual artifact that the audience takes in all at once, so that the argument as presented is fully developed and in final form. Moreover, whereas in a dialogue the participants function consecutively as arguer and as audience, in many situations these roles are far more specialized. Audience members may receive the 
argument and evaluate it as a whole, without contributing - at least directly - to its production. Whereas the commitments of dialogue partners either are known in advance or can be probed through the steps in the exchange, in many situations an audience's commitments can only be assumed or guessed at. Since audiences are seldom homogeneous, different members may have different starting points; it is difficult to know what the commitments of a heterogeneous audience are. And to make matters even more complicated, an arguer often addresses multiple audiences simultaneously. A member of parliament, for example, may direct his or her comments nominally to the presiding officer and his or her colleagues while actually intending them for the member's constituents who will read them in the newspaper or hear them on television. Or a president or prime minister might deliver to a domestic audience a message that really is intended to alert other nations to a change in its foreign policy. Whether the argument should be evaluated in relation to the addressed or to the intended audience is often unclear.

These difficulties and others are sometimes cited as weaknesses in the pragmadialectics project. But it is not appropriate to indict the approach for failing to accomplish what it never set out to do in the first place. Nor is it the case, for that matter, that pragma-dialectics has been confined exclusively to dialogue encounters. Interesting analyses have been conducted, for example, of arguments in newspaper advertisements (advertorials), of parliamentary debates, and of formal speeches (van Eemeren \& Garssen 2009; van Eemeren \& Houtlosser 1999). It may be the case that while the dialogue is the paradigm case of argument within this framework, aspects of pragma-dialectics may have wider reach and applicability than its designers had in mind initially. The more recent introduction of strategic maneuvering into the pragma-dialectical perspective enhances this possibility (van Eemeren \& Houtlosser 2002; van Eemeren 2010). That is the proposition we wish to examine in this contribution. Specifically, we wish to explore the applicability of pragma-dialectics to rhetorical argumentation by analyzing a prototypical example of what is considered a rhetorical text using the pragma-dialectical concept of strategic maneuvering.

The significance of applying pragma-dialectical approaches to rhetorical texts is that it calls into question the long-standing opposition between dialectic and rhetoric. The goal of the former often is thought to be belief; of the latter, action. Dialectic is about truth whereas rhetoric is about persuasion. Dialectic involves questions and answers; rhetoric, a discursive presentation. In dialectic, communication and influence are bidirectional; in rhetoric, they proceed only from the speaker to the audience. In recent years, however, more attention has been given to the similarities between dialectic and rhetoric as audience-based, nonformal modes of reasoning. This perspective is enhanced by demonstrating that an analytical method intended for one may also be of use for the other. 
in the "belief that the interests we share as human beings are far more powerful than the forces that drive us apart."

Accordingly, Obama pays homage to the constructive role of Islam in U.S. culture and history and proclaims it his duty "to fight against negative stereotypes of Islam wherever they appear." But this proclamation immediately creates a reciprocal obligation: "Just as Muslims do not fit a crude stereotype, America is not the crude stereotype of a self-interested empire." He takes pride in a series of American achievements and especially in the freedoms America affords to everyone, including Muslims. He concludes that "America holds within her the truth that regardless of race, religion, or station in life, all of us share common aspirations - to live in peace and security; to get an education and to work with dignity; to love our families, our communities, and our God." These, Obama asserts, are universal aspirations. Moreover, in the interconnected world of the 21st century, we are all affected by events in distant lands. Policymaking, therefore, should proceed from the premises of common humanity and global interdependence rather than from the history of antagonistic nations, tribes, and religions "subjugating one another in pursuit of their own interests".

Obama then applies this perspective to a series of issues that "we must finally confront together": violent extremism in all its forms; the relationships among Israelis, Palestinians, and the Arab world; halting the spread of nuclear weapons and reducing the world's nuclear stockpiles; the promotion of the democracy around the world; religious freedom, women's rights and economic development and opportunity. Within each of these topics Obama articulates the view of the U.S. and universalizes it by deriving it from principles he maintains apply to all people. Thus American beliefs and aspirations are contained within broader frameworks to which all people should resonate, Together we should move to address these common concerns, guided by the words of the Holy Bible, the Talmud, and the Koran. In an echo of Lyndon Johnson, Obama asserted, "We have the power to make the world we seek, but only if we have the courage to make a new beginning." And in an echo of John F. Kennedy's Inaugural Address, he admonished his listeners that "God's vision...must be our work here on Earth".

\section{Analysis}

The summary of the speech above is the foundation for our pragma-dialectical analysis. In order, we shall highlight the audiences and their commitments, reconstruct the arguments to reveal the standpoints and their relationships and discuss the strategic function of particular argumentative moves using the concept of strategic maneuvering. 


\subsection{Audiences and their commitments}

Conducting a pragma-dialectical analysis of a rhetorical text requires imagining the audience as a dialogue partner with the speaker. The audience's cognitive processing of the message and response to it are treated as if they were moves in a dialogue, and the audience is envisioned as if it were a single person (Walton 2007). But as van Eemeren (2010: 109-110) acknowledges, audiences are seldom homogeneous, they are rather often "composite", consisting of heterogeneous groups of people who differ in their backgrounds and positions. ${ }^{1}$ When an argumentative text addresses a composite audience, the situation is viewed as if the arguer were in dialogue simultaneously with multiple different interlocutors. The rhetor must be able, in effect, to imagine the entirety of the dialogue in advance, crafting the message as if it were anticipating the dialogue moves of the audience and seeking to influence the audience's final judgments.

Obama's audience in the Cairo speech was clearly composite. The speech's formal audience was the "Muslim world", to which Obama referred as if it were a homogeneous entity. Most of his discussion, however, is specific to Arab Muslims, or even more particularly to Muslims of the Middle East. There is no mention of the concerns of Northern African Muslims or of the Pashtun rebellion in Pakistan and Afghanistan, for example. It appears that Obama wants his audience to be seen more broadly than the specific issues he raises would suggest.

Another audience, most likely, is domestic. U.S. Muslims had been largely ignored during the 2008 election campaign. Obama did not set foot into a mosque, and he treated the false rumor that he himself was a Muslim as a "smear". Yet Obama did not wish to alienate U.S. Muslims. The emphasis throughout his career and campaign was to define the U.S. political community as inclusive rather than exclusive. He did not wish to alienate any religious or ethnic community or to place it outside the mainstream.

Meanwhile, many Americans not of the Muslim faith held views of Muslims that were overly influenced by the radical Islam professed by the terrorists of September 11,2001. There was evidence of increased prejudice and discrimination against Muslims. This too was unacceptable to Obama, both because it was morally unjustified and because it ran counter to his goal of emphasizing the pluralism of the American community. It was necessary therefore to "coach" many Americans to see their Muslim neighbors in a more constructive light.

Yet a third audience for Obama was other nations of the world. These included especially Israelis, who saw themselves to be constantly under a security threat but whose violent relationship with the Palestinians threatened to undercut the ability of the U.S. to be both a strong supporter of Israel and an honest broker for peace in the region. The audience also included nations of Western Europe who 
were encountering an increased Muslim population in ways less constructive than Obama would wish.

Each of these audiences began with different assumptions and commitments, but Obama saw a common flaw in them: they were stereotypical. They generalized to large populations from unrepresentative cases and were overdetermined in their assumptions about the viewpoints and motivations of their adversaries. What they lacked was the willingness to acknowledge that they might be wrong, the openness to alternative viewpoints, the ability to empathize with others of different views, and the preference for the pragmatic over the ideological. These were the commitments that Obama would seek to change, but he would be unable to succeed if he did not at least implicitly acknowledge them and make them the starting points for his discourse. In seeking to modify or reverse these commitments, Obama took advantage of other commitments that he attributed to his audiences: frustration with the stalemated state of affairs, willingness to challenge assumptions, refusal to be perceived as closed-minded, and willingness to extend to the new U.S. president a large degree of goodwill.

\subsection{Reconstructing the discourse: Standpoint analysis}

As the title of the speech suggests, Obama makes a case for new beginnings in the relationship between the U.S. and the Muslims around the world. He argues that it is time for new beginnings between the U.S. and the Muslim world and supports this main standpoint by means of arguments that relate to the seven issues that are currently sources of tension: extremism; the relationships among Israelis, Palestinians, and the Arab world; nuclear weapons, democracy; religious freedom, women's rights and modernity. He seeks a partnership based on mutual interests and mutual respect between the U.S. and Muslims. As he draws the guidelines of his administration's Middle East policy in relation to each of these issues, Obama points out characteristics of the current relationship that make the situation not satisfactory, he acknowledges the challenges facing the partnership he promotes as an alternative and asserts that this partnership is feasible in spite of these challenges. He also sketches the advantages that would be gained from it, mainly the resolution of the problems source of tension and getting closer to the world the U.S. and the Muslims seek. Obama's argumentation in support of his main standpoint follows the following structure:

1. It is time for new beginnings between the U.S. and the Muslim world

1.1 The current relationship between the U.S. and Muslims is not satisfactory

1.2a A partnership based on mutual interests and mutual respect between the U.S. and Muslims will be fruitful

1.2b A partnership based on mutual interests and mutual respect between the U.S. and Muslims is feasible in spite of the challenges 
Rhetorical scholars sometimes are accused of dwelling entirely in individual case studies, so it perhaps is appropriate that we explore the applicability of pragma-dialectics to rhetoric by considering a specific case. We have selected for this purpose U.S. President Barack Obama's speech at Cairo University in June 2009. It is a complex rhetorical event involving multiple messages and audiences. If pragma-dialectics can help to account for a message this complex, then a fortiori it should be able to do so for simpler cases.

\section{The case study: Obama in Cairo, June 2009}

During his campaign for the presidency, Obama had maintained that among the many unfortunate consequences of the conduct of the war on terror and especially of the war in Iraq was the fraying of relationships between the United States and the Muslim world. Too many Americans, he believed, stereotyped all Muslims as radical fanatics, and too many Muslims held dangerously stereotypical views of all Americans. As a result, it was difficult to achieve even the minimal level of understanding and trust on which national and global security depended. To focus attention to this problem, Obama pledged that if elected, he would deliver a major speech in a Muslim nation during his first year in office. The purpose of the speech would be to call attention to the question of the U.S. relationship with the Muslim world and to put specific issues on the agenda for public discussion.

After extensive deliberation, the white House selected Cairo as the venue. As it happened, the speech was one of several that Obama delivered overseas during 2009 in which he tried to recalibrate the role of the U.S. in the world. He consistently emphasized partnerships rather than hierarchies and called for multilateral rather than unilateral actions. He acknowledged past mistakes on the part of the United States even as he pointed to mistakes by others. He frequently identified the interests of the American people with those of people in other lands and argued that the common interests of humanity transcended the differences among peoples (Zarefsky Forthcoming).

The Cairo speech fits clearly within this pattern (Obama 2009). Titled "Remarks by the President on a New Beginning," the speech acknowledges that "the relationship between Islam and the West includes centuries of coexistence and cooperation," but goes on to identify as sources of current tension the legacy of colonialism, the Cold War, and "the sweeping change brought by modernity and globalization." Terrorists exploited these tensions on September 11, 2001, breeding reciprocal fear and mistrust. Consequently, he warns, we should not expect too much of a single speech, but we must commit to make a new start, 
The argument about the current relationship can support the standpoint independently of the other two arguments. After all, it is enough that one accepts that the current relationship is not satisfactory in order to accept that it is time for new beginnings between the U.S. and the Muslim world. While taken together the arguments about the fruitfulness and the feasibility of a partnership based on mutual interests and mutual respect can provide independent support for the standpoint, none of them can provide independent support for the standpoint on its own. The two arguments need to be taken together. In order to accept that it is time for a new relationship between the U.S. and the Muslim world one needs to accept both that the new relationship proposed is feasible and that it is fruitful.

Each of the three main arguments above is further supported by sub-arguments that relate to the seven issues source of tension. In supporting the sub-standpoint that the current relationship between the U.S. and Muslims is not satisfactory, Obama argues that

1.1 The current relationship between the U.S. and Muslims is not satisfactory

1.1.1 The current relationship is not satisfactory in what concerns the confrontation of violent extremism

1.1.2 The current relationship is not satisfactory in what concerns addressing the situation between Israelis, Palestinians and the Arab world

1.1.3 The current relationship is not satisfactory in what concerns addressing the rights and responsibilities of nations on nuclear weapons

1.1.4 The current relationship is not satisfactory in what concerns realizing the promise of democracy

1.1.5 The current relationship is not satisfactory in addressing the issue of religious freedom

1.1.6 The current relationship is not satisfactory in addressing women's rights

1.1.7 The current relationship is not satisfactory in what concerns benefiting from economic development and opportunity

Each of the sub-arguments can, on its own, provide enough support for the substandpoint and therefore warrant the main standpoint. For example, if one accepts that the current relationship is not satisfactory in what concerns addressing the issue of religious freedom, one accepts that the current relationship between the U.S. and Muslims is not satisfactory and therefore accepts that it is time for new beginnings between the U.S. and the Muslim world.

Similarly, in supporting the sub-standpoint that a partnership based on mutual interests and mutual respect between the U.S. and Muslims will be fruitful, Obama presents arguments that are related to the seven problematic issues and each of which can support the sub-standpoint independently. Obama argues that

1.2a A partnership based on mutual interests and mutual respect between the U.S. and Muslims will be fruitful 
1.2a.1 A partnership will be fruitful for confronting violent extremism

1.2a.2 A partnership will be fruitful for addressing the situation between Israelis, Palestinians and the Arab world

1.2a.3 A partnership will be fruitful for addressing the rights and responsibilities of nations on nuclear weapons

1.2a.4 A partnership will be fruitful for realizing the promise of democracy

1.2a.5 A partnership will be fruitful for addressing the issue of religious freedom

1.2a.6 A partnership will be fruitful for achieving equality for women

1.2a.7 A partnership will be fruitful for benefiting from economic development and opportunity

And in supporting the sub-standpoint that a partnership based on mutual interests and mutual respect between the U.S. and Muslims is feasible in spite of the challenges, he argues that

1.2b A partnership based on mutual interests and mutual respect between the U.S. and Muslims is feasible in spite of the challenges

1.2b.1 A partnership in confronting violent extremism is feasible in spite of the challenges

1.2b.2 A partnership in addressing the situation between Israelis, Palestinians and the Arab world is feasible in spite of the challenges

1.2b.3 A partnership in addressing the rights and responsibilities of nations on nuclear weapons is feasible in spite of the challenges

1.2b.4 A partnership in realizing the promise of democracy is feasible in spite of the challenges

1.2b.5 A partnership in addressing the issue of religious freedom is feasible in spite of the challenges

1.2b.6 A partnership in achieving equality for women is feasible in spite of the challenges

1.2b.7 A partnership in benefiting from economic development and opportunity is feasible in spite of the challenges

The reconstruction of Obama's argumentation demonstrates how skillfully the speech is crafted to appeal to a variety of audiences. The resort to multiple argumentation, ${ }^{2}$ as van Eemeren (2010:110) observes, is a strategic choice when addressing a composite audience. Acceptance of either sub-standpoint (1.1) (the current relationship between the U.S. and the Muslim world is not satisfactory) or sub-standpoints (1.2a) and (1.2b) (a partnership based on mutual interests and mutual respect between the U.S. and the Muslims is both fruitful and feasible in spite of the challenges) would be sufficient to warrant the acceptance of the main standpoint (it is time for new beginnings between the U.S. and the Muslim world). Furthermore, acceptance of the line of arguments that relates to any of the issues addressed would be sufficient to warrant the standpoint. Consequently, 
different segments of Obama's complex audience could reason via different paths to acceptance of the same main standpoint. For example, while someone who is concerned about the relationship between Israelis and Palestinians will be convinced that is time for new beginnings between the U.S. and the Muslim world because he accepts that the current relationship is not satisfactory in what concerns addressing the situation between Israelis, Palestinians and the Arab world, someone else, who is concerned about nuclear ambitions might be convinced of the same standpoint because he accepts that a partnership based on mutual interests and mutual respect will be fruitful for addressing the rights and responsibilities of nations on nuclear weapons and that such a partnership is feasible in spite of the challenges.

For Obama, every step in the argument is important - not because it is logically necessary in order to secure standpoint 1 , but because it elucidates a different aspect of the U.S. relationship with the Muslim world. In the speech, Obama announces his administration's position regarding matters of the U.S. foreign policy in the Middle East and argues in support of these positions. In the next section, we shall show how it is especially when Obama argues in support of his administration's policies that the complexity of the audience addressed becomes apparent.

\subsection{Strategic maneuvering}

When van Eemeren and Houtlosser introduced the concept of strategic maneuvering, they greatly enhanced the potential for application of pragma-dialectics to rhetorical discourse. Strategic maneuvering recognizes that the parties to an argument not only want to resolve the disagreement but to resolve it in their favor. While meeting their dialectical obligations - to respond to the other party, to carry the argument forward, and so on - they can make choices which will strengthen or weaken their chances of prevailing. The major concern of rhetorical discourse is persuasion, influencing an audience to accept the standpoint put forward. Therefore, rhetoric reflects the results of numerous strategic judgments; strategic maneuvering is essential to it.

Without necessarily meaning to be exhaustive, van Eemeren and Houtlosser identify three general parameters for strategic maneuvering: arguers maneuver in their topical selection, audience adaptation, and presentational devices. Each of the parameters is evident in Obama's Cairo speech. The following analysis will focus on the arguments that relate to the relationship between Israelis, Palestinians and the Arab world as examples of those strategic maneuvers that help Obama to defend his administration's foreign policy while sustaining the standpoint that it is time for new beginnings between the U.S. and the Muslim world.

While the overall structure of Obama's speech (as discussed in the previous section) sheds light on how the standpoint that it is time for new beginnings 
between the U.S. and Muslims is defended, a closer analysis of the argumentation in the speech reveals that Obama is also defending the terms of the partnership he promotes as a new beginning between the U.S and Muslims. He does so mainly by defending the positions of the U.S. administration as terms of this partnership. Given that disagreement over the standpoint that calls for new beginnings is in fact quite unlikely (after all, Muslims around the world are already convinced that it is time for new beginnings between them and the U.S.), it is not surprising that defending the controversial terms of the partnership promoted is more important for Obama than defending the already accepted claim that it is time for new beginnings.

In many parts of his speech, the arguments that Obama advances support implicit standpoints in which certain positions of his administration are advocated. These arguments usually defend the position by asserting that such a position would make the promoted partnership feasible and/or fruitful. For example, in what concerns the relationship between Israelis, Palestinians and the Arab world, Obama announces that the U.S. considers legitimate the aspirations of both people in states of their own. In supporting this position, he argues that such a position is instrumental for achieving peace between Israelis and Palestinians. The choice of this line of argument to defend the administration's position is a clear case of a strategic topical selection. Unlike other arguments that could justify the position that it is necessary to recognize the legitimacy of the aspirations of both people in states of their own, the argument about peace has the highest chance of success. This is the case, especially in view of the composite audience that the speech addresses. Unlike the argument about peace, other lines of defense would not be successful in convincing a group in the audience without alienating the other. For example, an argument that supports the administration's position by asserting the necessity to recognize the Palestinians' right to return to the lands out of which they were driven in 1948 would have been very appealing to an audience of Palestinians but not without alienating an audience of Israelis. An audience of Palestinians considers the recognition of the right of return necessary for a fair resolution to the Palestinian Israeli conflict and would have accepted Obama's position about recognizing the aspirations of both people had this position been supported by this argument. However, an audience of Israelis sees the Palestinians' right of return as a threat to the Jewish nature of their state and are most likely to reject the position announced had it been supported by an argument that recognizes the Palestinians' right of return. In a similar way, an argument about the necessity of accepting the facts on the ground would have appealed to Israelis but alienated Palestinians. Israelis, whose expanded state has become a fact on the ground, are more likely to accept the position than the Palestinians whose aspiration in a state of their own is often threatened by the facts on the ground imposed by Israel. Unlike the 
argument about the recognition of the Palestinians' right of return and that of the necessity of accepting facts on the ground, the argument that recognizing the aspirations of both Palestinians and Israelis is instrumental for achieving peace between the two people appeals to both audiences.

The argument about peace between Palestinians and Israelis does not only justify a key position that the Obama administration adopts in what concerns the Israeli Palestinian conflict. The argument about peace plays a role also in supporting the sub-standpoint that asserts the fruitfulness of the partnership promoted for addressing the situation between Israelis, Palestinians and the Arab world, and it lends support to the main standpoint that calls for new beginnings between the U.S. and Muslims consequently. By presenting the recognition of the right of both Israelis and Palestinians in states of their own as a term of the partnership promoted, Obama argues that the partnership will be fruitful for addressing the situation between Israelis, Palestinians and the Arab world (1.2a.2) because the U.S. position as part of it, namely that the U.S. recognizes the legitimacy of the aspirations of both Palestinians and Israelis, is instrumental for achieving peace between the two people.

A further examination of the strategic maneuvers Obama employs in defending his administration's positions reveals the complexity of the audience he addresses. Some of these maneuvers cannot be seen as strategic unless audiences other than the one addressed by standpoint (1) are also taken into account. While some positions, such as the situation for the Palestinian people is intolerable and the United States does not accept the legitimacy of continued Israeli settlements, are clearly effective in convincing Middle Eastern Muslims that the partnership that the U.S. is proposing is fruitful, other positions, such as the bond between the U.S. and Israel is unbreakable and Palestinians must abandon violence before negotiations can begin, do not seem to be effective with this particular audience. Arguments about the intolerability of the situation for the Palestinians and the illegitimacy of continued settlements draw from the commitments of the audience of Middle Eastern Muslims. By relying on them in his line of defense, Obama maneuvers strategically by adapting to this particular audience. Arguments that defend a strong bond between the U.S. and Israel and call for the necessity for Palestinians to abandon violence draw from commitments that cannot be considered to be assumed by an audience of Middle Eastern Muslims. In fact, the positions advocated in these arguments will most probably be counterproductive in addressing Muslims especially because they rely on the commitments of an audience of Israelis. Taking into account this group of the audience, the choice becomes a clear case of strategic maneuvering by adapting to the audience demand: the argument is strategically adapted to appeal to an audience of Israelis in an effort to gain at least their acquiescence to the standpoints that appeal to Muslims. 
Furthermore, taking the audience of Israelis into account is necessary to reveal the strategic maneuver in refering to the acts of Palestinians as violence. This choice of presentational device cannot be a strategic choice if Obama is attempting to convince Muslims around the world to join the partnership he promotes. Obama is certainly aware that the majority of Muslims, especially Middle Eastern Muslims, view the acts of Palestinians to which he refers as acts of legitimate resistance against the Israeli military occupation of Palestinian lands. This choice of the term used to present the acts of Palestinians alienates this audience and makes less convincing to them the argument that the partnership promoted is fruitful. The choice of term is however very opportune if an audience of Israelis is the target. Obama's choice reassures this audience that he is faithful to their concerns about security. This reassurance might be necessary for Obama not to alienate the Israelis who see some of his other positions to reflect an unprecedented affinity with Palestinians' aspirations. They need to have some of their own commitments recognized by Obama as real, especially if Obama wishes to reconcile them to making significant concessions to the Palestinians.

While convincing Muslims that it is time for new beginnings in their relationship with the U.S. is important in Obama's speech, the defense of the terms of these new beginnings is often more important. Despite the fact that the argument structure is multiple, the convincingness of the general standpoint may depend on the details of the cases to which it is linked. As the analysis of Obama's strategic maneuvering above shows, as Obama defends the terms of this relationship, he does not only address the audience of Muslims which is immediately involved in the new relationship, but he also addresses an audience of Israelis, who will be affected by this new relationship and who will be less likely to resist change if they find the proposed terms of the relationship acceptable. Given that the speech was considered by many as an announcement of the new administration's foreign policy towards the Middle East, it becomes evident that Obama cannot but address this audience too.

\section{Conclusion}

As the above analysis indicates, Barack Obama's June 4, 2009 speech at Cairo University can be analyzed using the approach and tools of pragma-dialectics. Doing so reconstructs the logic of Obama's argument and helps to make clear how he deals with the need to address multiple audiences simultaneously.

This is not to suggest that pragma-dialectics is necessarily the best tool to use for analyzing Obama's speech. Like any analytical instrument, it emphasizes certain features of the text and obscures others. Nor does every aspect of pragmadialectics lend itself well to this analysis. For example, mapping the sequences of 
dialogue moves is not practical in a situation without overt dialogue and when all the audience moves are attributed to it in advance by the arguer.

Still, demonstrating the applicability of pragma-dialectical analysis to rhetori$\mathrm{cal}$ argumentation is hardly trivial. As this example indicates, focusing on commitments (analogous to the opening stage in a dialogue) identifies the different starting points that members of a heterogeneous audience bring to the speech and makes clear the necessity for the speaker to respond in the same speech to these differing commitments. The emphasis on reconstructing argumentative discourse into the standpoint and the support for it makes very clear the interrelationship among sub-standpoints and whether the burden of proof is made easier or more difficult by the pattern by which the standpoint is justified. And the emphasis on strategic maneuvering highlights the delicacy of the situation and the importance of very specific choices of topic selection, presentational choice, and response to audience demand in order to be able to resolve the dispute in the arguer's own favor.

In short, then, applying pragma-dialectics to rhetorical argumentation suggests that an analytical framework Frans van Eemeren and his colleagues developed for argumentation modeled on the critical discussion may in fact be broadly applicable to argumentation in general.

\section{Notes}

1. Within what counts as a composite audience, van Eemeren makes a distinction between mixed audiences, in which the audience is heterogeneous with respect to the starting points of its members, and multiple audiences, in which the audience is heterogeneous with respect to the positions its members adopt (2010, p. 110).

2. In their textbook, van Eemeren, Grootendorst, and Snoeck Henkemans distinguish among three argument structures: multiple, coordinative, and subordinative arguments (van Eemeren et al., 2002: pp. 63-78). Multiple arguments contribute to the standpoint independently of one another. Therefore, there are many points of possible connection. This structure is especially attractive to Obama, because it provides a heterogeneous audience with many different routes to acceptance of the standpoint. The analysis makes clear why this is a good choice under the circumstances.

\section{References}

Eemeren, F.H. van. (2010). Strategic maneuvering in argumentative discourse. Amsterdam/ Philadelphia: John Benjamins Publishing Company.

Eemeren, F.H. van, \& Garssen, B.J. (2009). Strategic maneuvering with argument schemes in the European parliament. Proceedings of the OSSA conference 2009 [CD-ROM]. Windsor, ON: University of Windsor. 
Eemeren, F.H. van, \& Grootendorst, R. (2004). A systematic theory of argumentation. The pragma-dialectical approach. Cambridge: Cambridge University Press.

Eemeren, F.H. van, Grootendorst, R. \& Snoeck Henkemans A.F. (2002). Argumentation: Analysis, evaluation, presentation. Mahwah, NJ: Lauwrence Erlbaum Associates, Inc.

Eemeren, F.H. van, \& Houtlosser, P. (1999). William the Silent's argumentative discourse. In F.H. van Eemeren, R. Grootendorst, J.A. Blair \& C.A. Willard (Eds.), Proceedings of the Fourth Conference of the International Society for the Study of Argumentation (pp. 168-171). Amsterdam: Sic Sat.

Eemeren, F.H. van, \& Houtlosser, P. (2002). And always the twain shall meet. In F.H. van Eemeren \& P. Houtlosser (Eds.), Dialectic and rhetoric: The warp and woof of argumentation analysis (pp. 3-11). Dordrecht: Kluwer Academic.

Obama, B. (2009). "Remarks by the President on a New Beginning." Available at http://www.whitehouse.gov/the_press_office/Remarks_by_the_President_at_Cairo_ University_6_04_09.

Walton, D.N. (2007). Media argumentation: Dialectic, persuasion, and rhetoric. New York: Cambridge Univ. Press.

Walton, D.N., \& Krabbe, E.C.W. (1995). Commitment in dialogue: Basic concepts of interpersonal reasoning. Albany: State Univ. of New York Press.

Zarefsky, D. (forthcoming). The Obama phenomenon and the discourse of American foreign policy. In J.R. Mercieca \& J. Vaughn (Eds.), Obama's burden. College Station, TX: Texas A\&M Univ. Press. 